\title{
EIIdA
}

Revista Eletrônica de Estudos Integrados em Discurso e Argumentação

\section{ARGUMENTAÇÃO E IMAGINÁRIOS NA MÍDIA RELIGIOSA}

\section{Wilma Maria Pereira}

Resumo: Este trabalho discute a relação entre a configuração argumentativa e a formulação de imaginários sociodiscursivos a partir da análise do gênero notícia na Revista Ultimatoii. A análise está pautada nos pressupostos teórico-metodológicos da Análise do Discurso, sobretudo na Teoria Semiolinguística de Patrick Charaudeau (2007, 2008). A pesquisa incide sobre os procedimentos discursivos e semânticos (CHARAUDEAU, 2008) e as técnicas argumentativas (PERELMAN; OLBRECHTSTYTECA, 1996) utilizados por um sujeito psicossocial na encenação do seu discurso. Dessa configuração argumentativa, buscou-se apreender os imaginários sociodiscursivos construídos, a mudança de visada na divulgação das informações e a (re)configuração do gênero notícia que se apresentou como veículo substancial de um discurso normativo para o comportamento cristão.

Palavras-chave: Discurso. Argumentação. Imaginários Sociodiscursivos

\begin{abstract}
This article discusses the relationship between the argumentative configuration and the formulation of socio-discursive imaginaries based on the analysis of the news genre of the Revista Ultimato. The analysis was based on the theoretical and methodological assumptions of Discourse Analysis, especially in the Semiolinguistic Theory of Patrick Charaudeau (2007, 2008). The research focuses on the discursive and semantic procedures (CHARAUDEAU, 2008) and the argumentative techniques (PERELMAN; OLBRECHTS-TYTECA, 1996), used by a psychosocial subject in the staging of his discourse. From this argumentative configuration, we sought to apprehend the constructed socio-discursive imaginaries, the change of perspective in the dissemination of information and the (re) configuration of the news genre that presented itself as a substantial vehicle of a normative discourse for christian behavior.
\end{abstract}

Keywords: Discourses. Argumentation. Socio-discursive imaginary.

\footnotetext{
i Mestre em Letras pela Universidade Federal de Viçosa (UFV). Docente do Instituto Federal de Educação, Ciência e Tecnologia do Norte de Minas (IFNMG). E-mail: wilma.pereira@ifnmg.edu.br.

ii A Revista Ultimato, fundada em 1968, é um periódico cristão evangélico sem linha confessional determinada, que veicula textos representantes das diversas denominações cristãs (Luterana, Presbiteriana, Wesleyana, Batista, Metodista, Anglicana, Assembleia, entre outras). Ela mantém diálogo com a Igreja Católica, de quem também recebe contribuições autorais. Nesse sentido, a revista se autodenomina ecumênica ao tentar aproximar várias denominações religiosas (cf.: http://www.ultimato.com.br/revista/).
} 
EID\&A - Revista Eletrônica de Estudos Integrados em Discurso e Argumentação, Ilhéus, n. 13, jan/jun.2017.

\section{Introdução}

Sabe-se que, na atualidade, as mídias de uma maneira geral desempenham papel essencial na divulgação de informações no meio social. No entanto, ao se tratar do material midiático, não se deve desconsiderar o seu caráter "seletivo" na transformação dos fatos em acontecimentos. Esse tipo de procedimento confere às notícias uma identidade amalgamada, portadora de ideologias, crenças e imaginários - individuais ou coletivos resultando em um construto discursivo utilizado, às vezes, para agir sobre o outro. Ao considerar a possibilidade de "agir" sobre o outro no processo comunicativo, é possível adentrar o terreno da argumentação no qual se destaca o princípio de influência em que as "estratégias de linguagem são colocadas em jogo por um sujeito comunicante visando a elaborar um discurso capaz de transformar as crenças de um auditório fazendo-o aderir às teses apresentadas" (CHARAUDEAU, 2001, p. 157). A esse respeito, Guadanini considera que "a mídia, de modo geral, embora não possa impor às pessoas o que pensar, ela pode influenciá-las" (GUADANINI, 2013, p. 138). Assim, há de se considerar a mídia como mecanismo possivelmente capaz de promover a manipulação.

Vale ressaltar, ainda, que ao eleger determinados pontos de vista, a mídia silencia outros, por considerá-los menos importantes ou destoantes das verdades que pretende divulgar. É dessa forma que os discursos veiculados nos diversos meios midiáticos não devem ser considerados construtos ingênuos, uma vez que são resultantes de interesses que estão constantemente em jogo no curso do processo comunicativo e que são "encenados" a fim de se alcançar determinados objetivos. Assim, é com a intencionalidade voltada para esses possíveis objetivos que a mídia religiosa vem buscando maior alcance na divulgação de suas verdades e consenso para os conflitos de posição, sobretudo no que diz respeito a temas polêmicos que atravessam os dogmas da religião.

Nesse contexto, é relevante os estudos que buscam desvelar a articulação entre os recursos linguísticos e discursivos que podem funcionar como estratégias na encenação do discurso midiático religioso, potencializando o seu alcance persuasivo. Desse modo, o objetivo deste artigo é o de identificar imaginários sociodiscursivos que são construídos a partir dessa configuração argumentativa utilizada para "dizer” a homossexualidade 
EID\&A - Revista Eletrônica de Estudos Integrados em Discurso e Argumentação, Ilhéus, n. 13, jan/jun.2017.

no gênero notícia da Revista Ultimato, da Editora Ultimato, representante, como alega, do discurso cristão.

Para isso, procedemos à análise do corpus a partir das técnicas argumentativas (PERELMAN; OLBRECHTS-TYTECA, 1996), das premissas da Análise do Discurso e, principalmente, da Teoria Semiolinguística por ser propícia à investigação dos fenômenos que designam o conjunto da realidade linguageira na combinação entre o "dizer" e o "fazer". Essa combinação remete à ação de um sujeito intencional que tem em mente um projeto visando a influenciar alguém a respeito de uma determinada tese (CHARAUDEAU, 2005).

A análise que se segue apontou que os discursos foram "encenados" e (re)configurados, a fim de se defender um ponto de vista contrário à homossexualidade. Dessa (re)configuração discursiva do gênero, foi possível observar que a notícia analisada apresentou alteração na visada, passando de informativa a prescritiva, e servindo a um propósito comunicativo diferente daquele esperado para o gênero notícia, ou seja, serviu para sedimentar valores e crenças e para estabelecer regras de conduta consideradas necessárias à normatização dos comportamentos.

\section{A argumentação}

Segundo registros históricos, a Retórica teria surgido na sociedade grega como mecanismo capaz de, por meio do "bom" uso da palavra (eloquência) de um orador, mobilizar a ação de um auditório. Assim, do reconhecimento da potencialidade persuasiva do discurso surge uma nova disciplina que passa a ser ensinada como arte supostamente capaz de interferir sobre os comportamentos, crenças e atitudes de um interlocutor. A Retórica para os gregos era "a arte da eloquência e o estudo desta corresponde ao estudo do discurso e das técnicas utilizadas para persuadir, manipular ou convencer $\mathrm{O}$ auditório" (SOUZA, 2001, p. 160).

A Retórica encontra em Platão um de seus grandes questionadores. Isso porque, para o filósofo grego, o que certos oradores buscavam com o uso da Retórica era a instrumentalização da linguagem para fins persuasivos com o objetivo de potencializar os seus discursos, dissimular a verdade e confundir as pessoas ao sabor de suas conveniências. A esse respeito, Emediato (2001) assinala que esses oradores buscavam "manipular a linguagem, ampliar o seu poder de persuasão e colocá-la a serviço da política e dos interesses de quem 
EID\&A - Revista Eletrônica de Estudos Integrados em Discurso e Argumentação, Ilhéus, n. 13, jan/jun.2017.

Ihes pagava" (EMEDIATO, 2001, p. 161). Platão era contrário a essa apropriação da Retórica para "fins indevidos", praticada por esses oradores. Em lugar da prática de falseamento da realidade e "comércio" do discurso bem elaborado, Platão propõe a busca da verdade como fim último de realização da arte Retórica.

Com Aristóteles (384-322 a.C.) "a arte retórica é elevada à categoria de ciência" (CITELLI, 2002, p.10). Aristóteles trará a sua contribuição para a Retórica, sobretudo na análise dos mecanismos mais efetivos na constituição e na elaboração dos discursos. Ele buscou analisar esses mecanismos no processo compositivo dos textos não como mera técnica de elaboração dos discursos, mas como forma de operação desses elementos organizacionais na essência de um processo pelo qual o homem significa, interpreta e compartilha o mundo que o cerca.

Coube, portanto, a Aristóteles, o papel de ser um dos primeiros sistematizadores da Retórica, compreendida como instrumento do intelecto. Ele buscou organizar princípios metodológicos e técnicos objetivando identificar o que era, como se fazia e qual a aplicação dos procedimentos persuasivos no discurso, ou seja, buscou uma Retórica do raciocínio e da prova, aplicável a qualquer assunto. Para Souza, é com Aristóteles que "a Retórica perde a sua definição sofística de arte e eloquência e do "falar bem", de arte oratória enfim, para se tornar um conjunto de técnicas "racionais", visando a persuadir o auditório" (SOUZA, 2001, p. 162).

$\mathrm{Na}$ atualidade, destaca-se o trabalho, desenvolvido por Chaïm Perelman juntamente com Lucie Olbrechts-Tyteca que se dedicaram a elaborar a chamada "Nova Retórica", resultando na elaboração do Tratado da Argumentação (1958). O pioneirismo desses autores deve-se ao fato de não se limitarem a transpor acriticamente o conceito de dialética clássica para a atualidade. Buscaram, sobretudo, novas reflexões sobre o discurso argumentativo e introduziram os conceitos de auditório particular e universal contribuindo também para a análise da troca comunicativa.

Para Plantin (2008), um dos méritos da Nova Retórica é o de ter fundado o estudo da argumentação sob o prisma das chamadas técnicas argumentativas, o que forneceu à argumentação uma rica base empírica de esquemas, que configuram a especificidade dessa modalidade linguística" (PLANTIN, 2008, p. 54), ou seja, o inventário ou a classificação dos tipos de argumentos é uma das contribuições essenciais do Tratado da Argumentação. 
EID\&A - Revista Eletrônica de Estudos Integrados em Discurso e Argumentação, Ilhéus, n. 13, jan/jun.2017.

Nessa obra teórica, as técnicas argumentativas (esquemas argumentativos) são apresentadas sob dois aspectos: associativo (esquemas que aproximam elementos distintos e permitem estabelecer entre eles uma solidariedade) e dissociativo (técnicas de ruptura com o objetivo de dissociar elementos considerados como um todo). Dessa classificação, Perelman e Olbrecht-Tyteca (1958) partem para a constituição dos grupos de argumentos: os argumentos quase-lógicos, os argumentos baseados na estrutura do real e os argumentos de ligação que fundamentam a estrutura do real. A Nova Retórica inclui, ainda, considerações importantes sobre a importância dos lugares da argumentação (lugares comuns e lugares específicos) e dos acordos entre orador e auditório. Além disso, busca a análise dos esquemas argumentativos e discursivos que objetivam a adesão de um determinado público às teses apresentadas.

Desse modo, os estudos sobre argumentação ganham papel de relevância na análise dos discursos que circulam na sociedade ao fornecer mecanismos para a análise dos efeitos da comunicação. Neste artigo recortaremos do Tratado da Argumentação as técnicas argumentativas, a fim de inventariar os argumentos utilizados pelo enunciador da Revista Ultimato e os imaginários que os materializam no jogo discursivo.

Por sua vez, a Teoria Semiolinguística aborda a argumentação sob a perspectiva do Modo de Organização Argumentativo. Esse modo de organização pode ser considerado um dispositivo destinado a "fazer compreender como funciona a mecânica do discurso argumentativo" (CHARAUDEAU, 2008, p. 203), com base nos componentes e procedimentos organizados em "função das finalidades discursivas do ato de comunicação" (CHARAUDEAU, 2008, p. 74). Nesse contexto, o ato de argumentar fundamenta-se em um projeto de intencionalidade de um sujeito argumentante portador de uma proposta sobre o mundo que utilizará determinados mecanismos para influenciar um sujeito-alvo, ou seja, "é uma atividade discursiva que, do ponto de vista do sujeito argumentante, participa de uma dupla busca: a busca de racionalidade que tende a um ideal de verdade quanto à explicação de fenômenos do universo e a busca de influência que tende a um ideal de persuasão" (CHARAUDEAU, 2008, p. 206).

Em consonância com o Tratado da Argumentação, Charaudeau (2008) propõe em seu Modo de Organização do Discurso os procedimentos da encenação argumentativa que têm por finalidade validar a argumentação. São 
EID\&A - Revista Eletrônica de Estudos Integrados em Discurso e Argumentação, Ilhéus, n. 13, jan/jun.2017.

os procedimentos semânticos (valor dos argumentos), os discursivos (utilização de categorias da língua para produzir efeitos de discurso) e os composicionais (organizam o conjunto da argumentação).

Para este artigo, portanto, além das técnicas argumentativas propostas no Tratado da Argumentação, utilizaremos também os procedimentos semânticos que englobam os domínios de avaliação (verdade, ético, estético, hedônico, pragmático). Esses procedimentos são sustentados no consenso social e servem como mecanismos de validação dos argumentos em um dado contexto comunicativo. Da Teoria Semiolinguística utilizaremos, ainda, o conceito de imaginários sociodiscursivos que será apresentado no próximo tópico.

\section{Os imaginários sociodiscursivos}

Falar de imaginários é tratar de uma noção abstrata configurada no cerne das práticas linguageiras, por meio dos discursos de indivíduos socialmente situados. Esses indivíduos criam e recriam nas suas práticas cotidianas os valores, as crenças e os conhecimentos que serão colocados em prática e negociados entre eles em cada situação de comunicação. Os seus discursos são portadores de "sentidos sobre o mundo" e organizados em forma de "saberes" que são partilhados por um determinado grupo social.

Esses saberes estão, portanto, intimamente relacionados à noção de contrato comunicativo e serão invocados pelo sujeito ao se inscrever em uma dada situação comunicativa. Da relação desses saberes com a configuração do ato comunicativo, Charaudeau (2006) considera que "à medida que esses saberes, enquanto representações sociais, constroem o real como universo de significações, segundo princípios de coerência, falaremos em imaginários" (CHARAUDEAU, 2006, p. 203), ou seja, a Semiolinguística tratará da questão da representação social' ${ }^{1}$ sob a perspectiva dos imaginários sociodiscursivos.

Para isso, Charaudeau aborda a questão dos imaginários sob o prisma da distinção existente entre os conceitos de "real" e "realidade". Ele parte da consideração de que a "realidade nela mesma existe, mas não significa" (CHARAUDEAU, 2006, p. 203). A realidade é, então, para a Teoria Semiolinguística, a "matéria" de onde parte a construção do sujeito sobre as coisas do mundo. Ela depende para a sua significação de uma dupla relação: a

\footnotetext{
${ }^{1}$ Conceito elaborado pela Psicologia Social.
} 
EID\&A - Revista Eletrônica de Estudos Integrados em Discurso e Argumentação, Ilhéus, n. 13, jan/jun.2017.

relação "homem/realidade", por meio da experiência, e da relação entre o "EU/OUTRO", para a construção dos sentidos do mundo.

Dessa forma, a realidade depende do papel do sujeito para significar e é desse processo de significação criado pelo sujeito que surge, segundo Charaudeau (2007b), o chamado real significante do mundo² (CHARAUDEAU, 2007b, p. 2, trad. nossa). Esse real significado construído pelo sujeito é configurado na ação de um sujeito que, inserido em um contexto social, irá construir as suas significações com base em uma série de conhecimentos, crenças e valores característicos do contexto em que são produzidos os enunciados e, daí a noção de imaginários sociais, ou seja, uma construção coletiva que sedimenta a identidade de um grupo por meio de um universo de significações. Para Charaudeau, trata-se de:

[...] um modo de apreensão do mundo que nasce da mecânica das representações sociais [...] constrói a significação dos objetos do mundo, os fenômenos aí produzidos, os seres humanos e seus comportamentos, transformando a realidade em real significante ${ }^{3}$ (CHARAUDEAU, 2007b, p. 3, tradução nossa.)

Os imaginários são, então, as formas construídas pelo sujeito comunicante para dar significação ao mundo. Trata-se de um construto, de "uma imagem" da realidade que não só a "representa" mas também a constrói em função da interpretação e do universo de significações do sujeito. Destaca-se, mais uma vez, na teoria que ora usamos, uma mudança de paradigma na análise dos discursos, representada pela retomada do sujeito como constituinte do universo de construção e de interpretação dos discursos. Essa presença fundamental do sujeito no discurso nos remete à sugestão de Charaudeau (2006) ao criar a noção de imaginário sociodiscursivo. Para ele:

[...] tendo em vista que estes são identificados por enunciados linguageiros produzidos de diferentes formas, mas semanticamente reagrupáveis, nós os chamaremos de "imaginários discursivos" [...] e, considerando que circulam no interior de um grupo social, instituindo-se em normas de referência por seus membros, falaremos de imaginários sociodiscursivos" (CHARAUDEAU, 2006, p. 203).

\footnotetext{
${ }^{2}$ No original: “[...]le signifié n'est pas la réalité elle-même, mais une construction signifiante de la réalité. C'est cette construction de sens qu'on appellera le réel signifiant du monde [...] “.

3 No original: “L'imaginaire est un mode d'appréhension du monde qui naît dans la mécanique des représentations sociales, laquelle, on l'a dit, construit de la signification sur les objets du monde, les phénomènes qui s'y produisent, les êtres humains et leurs comportements, transformant la réalité en réel significant".
} 
EID\&A - Revista Eletrônica de Estudos Integrados em Discurso e Argumentação, Ilhéus, n. 13, jan/jun.2017.

Dessa forma, podemos considerar que os imaginários sociodiscursivos são construtos do universo social, resultantes da interferência discursiva de um sujeito sobre a realidade, cuja função é "classificar" as ações do mundo material. Além disso, eles apresentam a "palavra" como instrumento de ação sobre o mundo, ou seja, o seu significado é materializado por meio dos discursos, o que nos remete à consideração de Charaudeau (2007b), para quem o sintoma de um imaginário é o discurso4.

Concluindo, os imaginários são, para a Teoria Semiolinguística, o resultado de uma atividade de representação do mundo construída no universo do pensamento a fim de descrever, explicar e justificar os fenômenos do mundo e do comportamento humano.

\section{Breve consideração sobre a mídia religiosa}

Sabe-se que a mídia religiosa nos últimos anos tem buscado diversificar os seus campos de atuação com o intuito de ampliar cada vez mais o seu alcance. Dessa forma, torna-se cada vez mais comum a divulgação do discurso religioso por meio de revistas, programas televisivos, jornais, sites e aplicativos para dispositivos móveis, o que influencia significativamente o alcance das mensagens. Integrando esse espaço de "evangelização a distância", destacaremos neste artigo a utilização da mídia impressa por meio da análise do gênero notícia na Revista Ultimato.

Sabe-se que a circulação de mídia impressa no meio religioso está relacionada, principalmente, ao fortalecimento dos vínculos já existentes entre os fiéis e a denominação religiosa de sua filiação. Assim, se os fiéis não vão à igreja, a igreja se aproxima deles por meio de suas publicações responsáveis pela veiculação de suas doutrinas.

Do deslocamento do espaço restrito dos templos às grandes mídias, a evangelização reflete a influência de uma nova arquitetura social com a (re)configuração da fé que passa do espaço coletivo dos cultos e dos templos ao isolamento de um ritual doméstico e, assim, "uma nova igreja é criada, universal e virtual. Os templos são os próprios lares [...]" (GOMES, 2004, p. 5).

\footnotetext{
${ }^{4}$ No original: "[...] le symptôme d'um imaginaire est la parole [...]".
} 
EID\&A - Revista Eletrônica de Estudos Integrados em Discurso e Argumentação, Ilhéus, n. 13, jan/jun.2017.

Trata-se de uma nova cruzada", a "cruzada midiática" que busca fazer avançar novos métodos de evangelização dependentes dos aparatos telemidiáticos.

No cerne desses aparatos midiáticos está o discurso religioso, entendido, segundo proposta de Eni Orlandi (2011), como aquele no qual se faz ouvir a voz de um ente superior (Deus); assim, esse discurso seria "aquele em que fala a voz de Deus: a voz do padre - ou do pregador, ou, em geral, de qualquer representante seu - é a voz de Deus" (ORLANDI, 2011, p. 242-243). Esse "macro discurso" oriundo da voz divina apresenta as características de um discurso constituinte, conforme propõe Maingueneau (2008). Para este autor, esses discursos servem de fiadores para outros discursos ao se mostrarem legitimados por um ente superior de natureza inquestionável. A esse respeito, Franco (2013) considera que "como não há outros discursos que os precedem ou validem, os discursos constituintes têm a autonomia para gerir, por meio de sua enunciação, seu estatuto 'autofundado"' (FRANCO, 2013, p. 322).

Ainda em relação ao discurso religioso, deve-se considerar que não se trata de qualquer palavra, mas da palavra de "revelação" por meio da qual Deus fala aos homens. No Cristianismo, a palavra de revelação divina é a Bíblia, cuja interpretação "perfeita" decorre dos "especializados" responsáveis pela administração dos bens da fé. A essa interpretação "maior", institucionalizada e próxima ao sagrado, estão submetidos os sacerdotes e os leigos.

Vale ressaltar que ao sacerdote não é permitido nenhum tipo de inserção de sua subjetividade, pois ele é apenas o "mecanismo de transmissão" utilizado para a difusão da palavra sagrada aos fiéis, ou melhor, nas palavras de Orlandi (2011), "o representante da voz de Deus não pode modificá-la de forma alguma" (ORLANDI, 2011, p. 245), pois a interpretação aceitável antecede a existência tanto de leigos quanto de sacerdotes. Trata-se de uma "macro" palavra sagrada já consumada e apenas "administrada" pelos representantes do poder de Deus na Terra.

Nessa concepção, o discurso religioso institucionalizado se aproxima do discurso autoritário, fechado e não passível de novas interpretações, pois traduz apenas as "verdades" já reinterpretadas pelos porta-vozes especializados, responsáveis pelo trabalho religioso. No entanto, sob essa

\footnotetext{
5 Expedições medievais de inspiração cristã que tinham como intuito retomar a Terra Santa. 0 movimento recebe esse nome em referência à cruz, principal símbolo do Cristianismo, estampada nas vestimentas dos expedidores.
} 
EID\&A - Revista Eletrônica de Estudos Integrados em Discurso e Argumentação, Ilhéus, n. 13, jan/jun.2017.

suposta imparcialidade, escondem-se possíveis projetos de falas segundo os quais os "sacerdotes" podem exercer o seu controle sobre a devoção alheia. É nesse sentido que Franco (2013) aponta para certa heterogeneidade discursiva presente no discurso da mídia religiosa responsável por confundir os leitores, advinda da dificuldade de mapear a tênue divisão entre os "textos primeiros" (origem divina) e os "textos segundos" (discursos da hierarquia da igreja). Neste contexto, cabe aos fiéis reconhecer a existência de certa hierarquia a ser respeitada em nome da fé, ou seja, a palavra divina "chega" de Deus primeiro aos sacerdotes, compreendidos, aqui, segundo a noção de Bourdieu (1992). Posteriormente, a palavra divina deverá ser disseminada para os leigos, que deverão cumprir e obedecer aos preceitos que a palavra sagrada apresenta a fim de garantir a sua salvação.

Assim, o discurso religioso traduz um poder exercido sob os fiéis na forma de uma "troca simbólica", ou seja, a submissão do indivíduo aos preceitos da fé é uma espécie de "passaporte" que poderá garantir o acesso não só aos bens simbólicos da fé, mas também à vida eterna.

O discurso religioso veicula esse saber/poder a serviço da "fé", que constitui o princípio da oposição entre o sagrado (dominador) e o profano (dominado); a presença de um "representante de Deus" - o pastor, por exemplo, nas igrejas evangélicas - assinala nesse discurso a existência dessa assimetria entre o espiritual (Deus) e o temporal (homem). Segundo Orlandi (2011), é nessa assimetria que o mundo espiritual domina o temporal ou, traduzindo de outra forma, o "mundo espiritual" pode ser um regulador das relações humanas, "[...] favorecendo que se instale uma certa harmonia que possibilita o convívio social" (PEREIRA, 2008, p. 99), ou seja, o discurso religioso pode trazer em si visões de mundo orientadas e materializadas sob a perspectiva religiosa para regular e direcionar práticas e comportamentos sociais.

Com base nessas considerações, procedemos à análise da notícia7 "Pastores gays e pastoras lésbicas na igreja Luterana Americana", publicada na edição nov./dez. de 2009, na Revista Ultimato, identificando a relação entre a argumentação e a construção dos imaginários sociodiscursivos.

\footnotetext{
6 Os sacerdotes para Bourdieu (1992) representam a "fé" institucionalizada, ao contrário dos profetas que representam o "extraordinário", o novo, não institucionalizado.

7 Em função do espaço destinado à publicação, apresentaremos a análise de apenas uma notícia, recorte de uma pesquisa realizada com notícias da mídia religiosa coletadas entre 2009 e 2014 .
} 
EID\&A - Revista Eletrônica de Estudos Integrados em Discurso e Argumentação, Ilhéus, n. 13, jan/jun.2017.

\section{A argumentação e a construção de imaginários no gênero notícia}

A notícia selecionada para este artigo tem como tema a votação que teria acontecido na Igreja Luterana Americana, com a finalidade de decidir sobre a aceitação ou não de líderes homossexuais na referida igreja. A temática, ao ser apresentada ao leitor, busca atender a um duplo interesse (contrato de captação): um interesse cognitivo (querer-saber) relacionado ao dado factual supostamente novo, e o outro, um interesse emotivo, supostamente desencadeado pela questão "moral" suscitada pelo título e fermentado pelas inclinações afetivas do auditório que reconhece a informação como controversa e, por isso, pertinente para o seu grupo de pertencimento. Nos termos de Charaudeau (2007a), podemos falar em potencial de imprevisibilidade pelo qual uma informação pode provocar uma "perturbação" no sistema de valores do leitor, suscitando o seu interesse por uma determinada notícia.

A saliência será, aqui, produzida pelo fato de que o acontecimento escolhido veio perturbar a tranquilidade dos sistemas de expectativas do sujeito consumidor da informação, o que levará a instância midiática a pôr em evidência o insólito ou particularmente notável. O acontecimento midiático será então reinterpretado em função do potencial de pregnância do receptor, isto é, de sua aptidão em recategorizar seu sistema de inteligibilidade e em redramatizar seu sistema emocional (CHARAUDEAU, 2007a, p. 102-103).

Com base no potencial de imprevisibilidade, é possível dizer que o efeito de sentido produzido pelo título da notícia "Pastores gays e pastoras lésbicas na Igreja Luterana Americana" não se restringe apenas às informações trazidas ou contidas nesse enunciado, ou seja, a informação de que a igreja luterana americana a partir daquela data seria favorável à presença de homossexuais como líderes da igreja. Incide também sobre um sistema de valores e crenças cristalizados que será estremecido pelo fato supostamente novo que interpela o leitor a um "posicionamento" com base em suas emoções (perplexidade, dúvida, consternação).

A implicação de que o fato noticiado pode ter reflexos diretamente sobre a sua vida busca levar o leitor a problematizar a questão e suscita uma "responsabilização imaginária" posto que a aceitação de lideranças homossexuais na igreja luterana americana sugere uma possível inversão da conduta moral sustentada pela maioria das igrejas cristãs. Assim, a nova situação veiculada no fato noticioso entra em confronto com o tradicionalismo cristão promovendo certa tensão dentro desse universo 
EID\&A - Revista Eletrônica de Estudos Integrados em Discurso e Argumentação, Ilhéus, n. 13, jan/jun.2017.

contextual, provocada pelo encontro dos valores mais conservadores e as proposições "ser homossexual" e "ser líder evangélico", portadoras de uma visão mais inovadora e flexível.

Em relação a essas duas proposições, é possível afirmar que uma proposição verdadeira não pode contradizer outra também dita verdadeira. Segundo Perelman \& Olbrechts-Tyteca (1996), pelo princípio da não contradição, as duas proposições não podem ser verdadeiras, logo, uma delas haverá de ser considerada falsa, sem valor, pois a proposição (1), ser homossexual, é incompatível com a proposição (2), ser ministro de Deus, dentro de uma lógica cristã mais conservadora. Dessa forma, quando as teses apresentam condutas incompatíveis, há a necessidade de se renunciar uma a fim de se preservar a outra.

Para Charaudeau (2008) as proposições dessa ordem são inseridas num modo de raciocínio dedutivo e explicativo que interpela o leitor em favor de uma escolha, posto que as duas proposições são excludentes entre si e apresentam sentidos incompatíveis dentro da lógica da maioria das denominações cristãs. Ainda, segundo Perelman \& Olbrechts-Tyteca (1996), uma proposição pode ser admitida ou afastada, porque não é considerada oportuna, socialmente útil, justa ou equilibrada.

A tentativa de se defender uma "verdade" insere a notícia no modo de organização argumentativo segundo o qual um enunciador desenvolve um raciocínio por meio de procedimentos argumentativos visando a atingir o seu interlocutor. Essa manobra discursiva fica evidente na alteração feita pelo enunciador ${ }^{8}$ de uma visada de informação (fazer/saber) para uma visada argumentativa (fazer/crer). A seguir, apresentaremos a relação entre os argumentos utilizados pelo enunciador e os imaginários por eles produzidos identificados na notícia analisada.

\footnotetext{
${ }^{8} \mathrm{Na}$ notícia analisada percebe-se a presença de várias vozes oriundas de diversos domínios sociais (jornalístico, psiquiátrico, religioso) que se entrecruzam e convergem para uma mesma ordem de significação. Assim, vozes de pastores, autores de livros e especialistas são articuladas para defender um mesmo ponto de vista, enquanto as vozes contrárias são silenciadas e apenas mencionadas como os "outros".
} 
EID\&A - Revista Eletrônica de Estudos Integrados em Discurso e Argumentação, Ilhéus, n. 13, jan/jun.2017.

\section{Quadro 1 - Relação argumentos e imaginários}

\begin{tabular}{|c|c|c|}
\hline Referência textual & Argumento & Imaginário construído \\
\hline $\begin{array}{l}\text { 1) "Os homens em vez de terem } \\
\text { relações sexuais normais cada qual } \\
\text { com sua mulher, arderam de paixão } \\
\text { uns pelos outros, homens praticando } \\
\text { coisas vergonhosas com outros } \\
\text { homens" } \\
\text { (Romanos 1.27) }\end{array}$ & Citação bíblica & $\begin{array}{l}\text { Prática anormal (conduta } \\
\text { patológica), } \quad \text { coisa } \\
\text { vergonhosa (valor social } \\
\text { negativo). } \\
\text { Contrária à lei natural. }\end{array}$ \\
\hline $\begin{array}{l}\text { 2)"A prática do homossexualismo é } \\
\text { pecaminosa, tanto porque perverte } \\
\text { a criação original de Deus com } \\
\text { respeito à sexualidade com vistas à } \\
\text { união sexual, quanto porque } \\
\text { significa ingratidão em relação a } \\
\text { Deus quanto à maneira como nos } \\
\text { criou individualmente". }\end{array}$ & $\begin{array}{ll}\text { Citação do } \\
\text { Dicionário de } \\
\text { Ética Cristã }\end{array}$ & $\begin{array}{lr}\text { Prática } & \text { pecaminosa, } \\
\text { perversão } & \text { (conduta } \\
\text { patológica), } & \text { contrária à lei } \\
\text { natural } & \end{array}$ \\
\hline $\begin{array}{l}\text { 3) Ao se referir aos pecadores }[. . .] \text {, } \\
\text { Paulo nomeia as suas perversões. }\end{array}$ & $\begin{array}{l}\text { Figura de } \\
\text { presença }\end{array}$ & $\begin{array}{l}\text { Pecado/Prática pervertida } \\
\text { (comportamento } \\
\text { patológico) }\end{array}$ \\
\hline $\begin{array}{l}\text { 4)"A sensação sexual contrária é o } \\
\text { termo coletivo para "modos de } \\
\text { comportamento afastado do } \\
\text { normal, especialmente } \\
\text { homossexualidade" }\end{array}$ & Definição & $\begin{array}{l}\text { Prática contrária, anormal } \\
\text { (conduta patológica) }\end{array}$ \\
\hline
\end{tabular}

Fonte: Elaboração própria

Nos tópicos (1) e (2) do quadro acima aparece a citação, procedimento discursivo que funciona como fonte de autenticidade ao inserir no discurso marcas de emissões de outrem, consideradas válidas para produzir um efeito de verdade. A utilização desse procedimento na notícia reforça a construção de um pretenso valor de verdade por meio da referência feita à Bíblia, ao Dicionário de Ética Crista e ao Dicionário de Psicologia, ao mesmo tempo em que invoca o imaginário da homossexualidade como anormalidade, prática vergonhosa, perversão, contrária à lei natural. Por sua vez, o argumento de presença é uma noção que invoca uma figura, uma lenda, uma parábola para trazer à consciência o objeto do discurso (PERELMAN; OLBRECHTS-TYTECA, 1996). É o que acontece no exemplo (3) com a invocação da figura do apóstolo Paulo, comumente utilizado no discurso religioso quando se pretende "doutrinar" modelos de relacionamento, sobretudo por representar uma conduta de santificação do corpo e de castidade. A utilização desse argumento reforça o imaginário da relação entre homossexualidade e perversão. 
EID\&A - Revista Eletrônica de Estudos Integrados em Discurso e Argumentação, Ilhéus, n. 13, jan/jun.2017.

Finalmente, o exemplo (4) apresenta o procedimento de definição que serve para produzir um efeito de evidência. Esse efeito de evidência pode ser observado na notícia não só no "valor" dos conceitos definidos, mas também na alta recorrência desse procedimento no texto (quase a metade da página destinada à notícia) e no apelo visual que os reforça ao apresentá-los em um quadro isolado no final da página. Observa-se que as definições apresentadas convergem para criar o mesmo efeito de sentido, ou seja, conectar a homossexualidade ao imaginário da anormalidade, da patologia.

Desta breve relação entre argumentos e imaginários, é possível inferir que a notícia analisada não é apenas um meio de divulgação de informações sobre assuntos que possam interessar ao público leitor de forma geral. Sob o pretexto da informação (Sessão Mais que Notícias), circulam elementos cujo objetivo é defender valores heteronormativos como padrão de comportamento, ao mesmo tempo em que possibilitam inferências de valor negativo para a homossexualidade. Verificamos, ainda, que as notícias foram reconfiguradas em função da intenção comunicativa do enunciador, passando de uma visada de informação (fazer/saber) para uma visada de prescrição (dever/fazer). Essa mudança fica melhor evidenciada no quadro a seguir.

Quadro 2 - Reconfiguração do gênero notícia

\begin{tabular}{|c|c|c|}
\hline Elemento & $\begin{array}{c}\text { O que se espera do } \\
\text { gênero }\end{array}$ & Como aparece na Revista Ultimato \\
\hline Da finalidade & $\begin{array}{c}\text { Visada } \\
\text { de informação }\end{array}$ & $\begin{array}{c}\text { Visada } \\
\text { de prescrição }\end{array}$ \\
\hline $\begin{array}{c}\text { Da identidade dos } \\
\text { participantes }\end{array}$ & $\begin{array}{c}\text { Instância informante } \\
\text { Instância cidadã (mais } \\
\text { ampla) }\end{array}$ & $\begin{array}{c}\text { Instância argumentante } \\
\text { Instância cristã } \\
\text { (grupo menor) }\end{array}$ \\
\hline Do propósito & $\begin{array}{c}\text { Acontecimentos do } \\
\text { espaço público }\end{array}$ & Doutrinação \\
\hline Das & Impressa & Impressa \\
\hline
\end{tabular}

Fonte: Elaboração própria 
EID\&A - Revista Eletrônica de Estudos Integrados em Discurso e Argumentação, Ilhéus, n. 13, jan/jun.2017.

A esse respeito, é notável como alguns discursos que aparentemente não têm função prescritiva podem ser manejados com finalidade de sedimentar determinados pontos de vista, como ocorreu na notícia com os imaginários contrários à homossexualidade: prática contrária à lei natural, anormalidade, perversão, prática vergonhosa, pecado, patologia. Trata-se, portanto, de uma tentativa de agir sobre as "crenças e as representações do outro sem que a visada argumentativa do discurso seja assumida pelo sujeito comunicante" (EMEDIATO, 2015, p. 78)

Destaca-se desse processo de categorização a implicação que esses "nomes" são capazes de suscitar no meio social. Isso acontece porque por meio do processo de "nomear" alguém ou alguma coisa é possível também estabelecer uma relação entre identidade pessoal e sociedade (BORGES, 2015). Para a referida autora, "nomear algo é, portanto, uma operação social, através da qual se realiza a construção social das coisas e se contribui para a estruturação do mundo no qual ela é reconhecida" (BORGES, 2015, p. 179). Assim, ao "categorizar" o indivíduo homossexual por meio de imaginários negativos, a notícia ajuda a reforçar no discurso religioso a categoria "marginal" desse indivíduo ao mesmo tempo em que delimita fronteiras e limites a serem mantidos em relação ao indivíduo homossexual, ou seja, serve à manutenção de uma ordem já instituída que continuará a dificultar o processo de "aceitação" desses indivíduos no corpo social (BORGES, 2015). No caso da notícia analisada, a ordem a ser mantida diz respeito aos comportamentos considerados aceitáveis e já cristalizados para os valores cristãos.

Dessa forma, vale salientar que os imaginários reforçam, por meio da utilização do processo de nomeação, uma "ideologia" amalgamada ao discurso noticioso que será cada vez mais fortalecida através do "hábito". Segundo Pêcheux (2009), é a ideologia que fornece as evidências que auxiliam os indivíduos a "reconhecer" significação dada aos elementos do mundo, e o autor acrescenta ainda que "o sentido de uma palavra, de uma expressão, de uma proposição não existe "em si mesmo" (isto é, em sua relação transparente com a literalidade do significante), mas, ao contrário, é determinado pelas posições ideológicas que estão em jogo no processo sócio-histórico" (PÊCHEUX, 2009, p. 146), ou seja, sob a suposta "transparência da linguagem" estão outros dizeres que objetivam direcionar os sujeitos para a adesão de modelo de comportamento que aniquila a homossexualidade por considerá-la patológica, contrária às leis naturais, anormal etc. Vale ressaltar, ainda, que ao "dizer" a 
EID\&A - Revista Eletrônica de Estudos Integrados em Discurso e Argumentação, Ilhéus, n. 13, jan/jun.2017.

homossexualidade, a mídia religiosa analisada a inscreve em um enquadramento apreciativo sob o qual circulam pontos de vistas subjetivos advindos dessa atribuição, capazes de mascarar outras perspectivas possíveis para o elemento “nomeado" (EMEDIATO, 2013).

\section{Considerações finais}

Neste artigo buscamos apontar imaginários sociodiscursivos construídos a partir da configuração argumentativa no gênero notícia da Revista Ultimato. Para isso, utilizamos como aporte teórico-metodológico a Teoria Semiolinguística e as técnicas argumentativas propostas por Perelman \& Olbrechts-Tyteca (1996). Verificamos que a notícia foi (re)configurada em função da intenção comunicativa do enunciador, passando de uma visada de informação para uma visada de prescrição. Em relação à argumentação, foram identificados os seguintes imaginários sociodiscursivos vinculados à homossexualidade: prática contrária à lei natural, anormal, perversão, prática vergonhosa, patologia, pecado. Dessa forma, consideramos que a mensagem veiculada sob o propósito de "informar" (fazer/saber) foi manejada sob uma orientação argumentativa (fazer/crer) com a finalidade de sedimentar pontos de vista contrários à homossexualidade, mostrando-se também argumentativa. Dessa análise, podese inferir que apesar de atualmente algumas denominações cristãs apresentarem um discurso mais "maleável” em relação à homossexualidade, ainda é cedo para dizer que ele tenha algum efeito na prática.

\section{Referências}

BOURDIEU, Pierre. A economia das trocas simbólicas. São Paulo: Perspectiva, 1992.

BORGES, Carolina. Sentidos para a homossexualidade. In: BARROS, Diana Pessoa; LARA, Glaucia Proença; LIMBERTI, Rita Pacheco (Org.). Discurso e desigualdade social. São Paulo: Contexto, 2015. p. 179-199.

CITELLI, Adilson. Linguagem e persuasão. São Paulo: Ática, 1991. (Série Princípios)

CHARAUDEAU, Patrick. Uma teoria dos sujeitos da linguagem. In: MARI, Hugo; MACHADO, Ida Lucia; MELLO, Renato (Org.). Análise do discurso: fundamentos e práticas. Belo Horizonte: Núcleo de Análise do Discurso-FALE/UFMG, 2001. p. 21-37. 
EID\&A - Revista Eletrônica de Estudos Integrados em Discurso e Argumentação, Ilhéus, n. 13, jan/jun.2017.

. Uma análise semiolinguística do texto e do discurso. In: PAULIUKONIS, Maria Aparecida Lino; GAVAZZI, Sigrid (Org.) Da língua ao discurso: reflexões para o ensino. Rio de Janeiro: Lucerna, 2005. p. 11-27.

. Discurso Político. São Paulo: Contexto, 2006.

. Discurso das Mídias. São Paulo: Contexto, 2007a.

. Les stéréotypes, c'est bien. Les imaginaires, c'est mieux. 2007b. Disponível em: http://www.patrick-charaudeau.com. Acesso em: 16 nov. 2016.

. Linguagem e Discurso: modos de organização. Trad. Angela S. M. Corrêa. São Paulo: Contexto, 2008.

EMEDIATO, Wander. A construção da opinião da mídia: argumentação e dimensão argumentativa. In: EMEDIATO, Wander (Org.). A construção da opinião na mídia. Belo Horizonte: FALE/UFMG, 2013. p. 317-335.

FRANCO, Eduardo. Opinião no jornalismo religioso: uso de dogmas e falácias como estratégia argumentativa. In: EMEDIATO, Wander (Org.). A construção da opinião na mídia. Belo Horizonte: FALE/UFMG, 2013. p. 317-335.

GOMES, Pedro Gilberto. Processos midiáticos e construção de novas religiosidades. Cadernos I.H.U. Instituto Humanitas Unisinos, São Leopoldo, ano 2, n. 8, p. 1-26, 2004.

GUADANINI, Sandra Magna. A construção da opinião através da designação nas revistas informativas. In: EMEDIATO, Wander (Org.). A construção da opinião na mídia. Belo Horizonte: FALE/UFMG, 2013. p. 137-155.

MAINGUENEAU, Dominique. Polifonia e cena de enunciação na pregação religiosa. In: LARA, Graça. MACHADO, Ida Lucia; EMEDIATO, Wander (Org.). Análises do discurso hoje. V. I. São Paulo: Lucerna, 2008.

ORLANDI, Eni. A linguagem e seu funcionamento. Campinas: Pontes, 2011.

PÊCHEUX, Michel. Semântica e Discurso. Campinas: Editora da Unicamp, 2009.

PEREIRA, José Carlos. Religião e poder: os símbolos do poder sagrado. Revista Eletrônica de Ciências Sociais, ano 2, v. 3, p. 80-107, 2008.

PERELMAN, Chaïm; OLBRECHTS-TYTECA, Lucie. Tratado da Argumentação: a nova Retórica. Trad. Maria Ermantina Galvão Pereira. São Paulo: Martins Fontes, 1996.

PLANTIN, Christian. A argumentação. São Paulo: Parábola Editorial, 2008.

SOUZA, Wander Emediato de. Retórica, argumentação e discurso. In: MARI, Hugo; MACHADO, Ida Lucia; MELLO, Renato de (Org). Análise do discurso: fundamentos e práticas. Belo Horizonte: Núcleo de Análise do discurso - FALE/UFMG, 2001. p. 157-177. 
EID\&A - Revista Eletrônica de Estudos Integrados em Discurso e Argumentação, Ilhéus, n. 13, jan/jun.2017.

Anexo: Pastores gays e pastoras lésbicas na Igreja Luterana Americana



Fonte: Revista Ultimato, ago-set/2009, p. 17.

Forma de citação sugerida:

PEREIRA, Wilma Maria. Argumentação e imaginários na mídia religiosa. EID\&A Revista Eletrônica de Estudos Integrados em Discurso e Argumentação, Ilhéus, n. 13, p. 209-226, jan/jun.2017. 